\title{
Cloud optical thickness and liquid water path - does the $k$ coefficient vary with droplet concentration?
}

\author{
J.-L. Brenguier ${ }^{1}$, F. Burnet ${ }^{1}$, and O. Geoffroy ${ }^{2}$ \\ ${ }^{1}$ CNRM/GAME, Météo-France/CNRS, URA1357, Toulouse, France \\ ${ }^{2}$ Royal Netherlands Meteorological Institute (KNMI), De Bilt, The Netherlands \\ Received: 3 December 2010 - Published in Atmos. Chem. Phys. Discuss.: 11 February 2011 \\ Revised: 26 August 2011 - Accepted: 29 August 2011 - Published: 21 September 2011
}

\begin{abstract}
Cloud radiative transfer calculations in general circulation models involve a link between cloud microphysical and optical properties. Indeed, the liquid water content expresses as a function of the mean volume droplet radius, while the light extinction is a function of their mean surface radius. There is a small difference between these two parameters because of the droplet spectrum width. This issue has been addressed by introducing an empirical multiplying correction factor to the droplet concentration. Analysis of in situ sampled data, however, revealed that the correction factor decreases when the concentration increases, hence partially mitigating the aerosol indirect effect.
\end{abstract}

Five field experiments are reanalyzed here, in which standard and upgraded versions of the droplet spectrometer were used to document shallow cumulus and stratocumulus topped boundary layers. They suggest that the standard probe noticeably underestimates the correction factor compared to the upgraded versions. The analysis is further refined to demonstrate that the value of the correction factor derived by averaging values calculated locally along the flight path overestimates the value derived from liquid water path and optical thickness of a cloudy column, and that there is no detectable relationship between the correction factor and the droplet concentration. It is also shown that the droplet concentration dilution by entrainment-mixing after $\mathrm{CCN}$ activation is significantly stronger in shallow cumuli than in stratocumulus layers. These various effects are finally combined to produce the today best estimate of the correction factor to use in general circulation models.

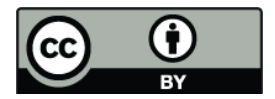

Correspondence to: J.-L. Brenguier (jlb@meteo.fr)

\section{Introduction}

Since Twomey $(1974,1977)$ speculated that aerosol of anthropogenic origin might enhance cloud albedo, (the socalled first aerosol indirect effect), many attempts were made to observationally corroborate the hypothesis and to develop parameterizations in general circulation models (GCM) for quantifying the Twomey effect at the global scale. Ship tracks observed from satellite (Coakley et al., 1987; Durkee et al., 2000, and the paper series of the MAST special issue therein) provided the first evidence of cloud microphysical impacts on cloud radiative properties. The CLOUDYCOLUMN experiment during ACE-2 (Raes et al., 2000) was specifically designed as a column closure experiment between aerosol, cloud microphysics and cloud radiative properties in marine stratocumulus clouds, North of the Canary Islands (Brenguier et al., 2000a). In situ measurements of aerosol, cloud condensation nuclei $(\mathrm{CCN})$ and cloud microphysics combined with independent remote sensing measurements of cloud radiative properties from above the cloud layer corroborated the expected relationships between CCN concentration, cloud droplet number concentration (CDNC) and cloud optical thickness (Brenguier et al., 2000b).

More recently, however, a series of controversial papers relying on in situ microphysical measurements suggested that the first aerosol indirect effect might be mitigated because of a relationship between the width of the droplet spectrum and CDNC, that was not anticipated by Twomey (Liu and Daum, 2002; Pawlowska et al., 2006; Liu et al., 2008; and references therein). This long series of papers originate from the seminal Martin et al. (1994) article, although Martin et al. study was limited to measurements in marine stratocumulus and restricted to undiluted cloud samples.

Published by Copernicus Publications on behalf of the European Geosciences Union. 
In this paper, in situ measurements of cloud microphysics are carefully revisited to better characterize instrumental artefacts, the impact of entrainment mixing, and ascertain a possible relationship between CDNC and the droplet spectrum width that might modulate the Twomey effect.

\section{Parameterization of the Twomey effect in GCMs}

In GCMs, a parameterization of the first aerosol indirect effect establishes a link between the calculations of cloud microphysics and of radiative transfer. It relies on predictions of the liquid water path (LWP) and CDNC to derive cloud optical thickness.

In liquid water clouds, albedo scales with cloud optical thickness, $\tau$, that expresses as (Hansen and Travis, 1974; Stephens, 1978):

$$
\begin{aligned}
\tau & =\int_{0}^{H} \sigma_{\mathrm{ext}}(h) d h=\int_{0}^{H} \pi \int_{0}^{\infty} Q_{\mathrm{ext}}(x) n(r, h) r^{2} d r d h \\
& =\int_{0}^{H} \pi Q_{\mathrm{ext}}(\bar{x}) N(h) r_{2}^{2}(h) d h=\int_{0}^{H} \pi Q_{\mathrm{ext}}(\bar{x}) M_{2}(h) d h
\end{aligned}
$$

where $\sigma_{\text {ext }}\left(\mathrm{m}^{-1}\right)$ is the light extinction, $h$ is the height above cloud base, $H$ is the cloud depth, $n(r) d r$ is the droplet size distribution, $r_{2}$ is its mean surface radius, $N=\int n(r) d r$ is the total cloud droplet number concentration, $x=2 \pi r / \lambda$ is the size parameter, $\bar{x}$ is its effective mean value, $Q_{\text {ext }}$ is the Mie efficiency factor (van de Hulst, 1957), and $M_{2}$ is the second moment of the droplet spectrum.

In a GCM, clouds are characterized by their liquid water path, $W$, which is the vertical integral of the liquid water content (LWC) :

$$
\begin{aligned}
W & =\int_{0}^{H} q_{\mathrm{c}}(h) d h=4 / 3 \pi \rho_{\mathrm{w}} \int_{0}^{H} N(h) r_{3}^{3}(h) d h \\
& =4 / 3 \pi \rho_{\mathrm{w}} \int_{0}^{H} M_{3}(h) d h,
\end{aligned}
$$

where $q_{\mathrm{c}}=4 / 3 \pi \rho_{\mathrm{w}} N r_{3}^{3}$ is the LWC, $\rho_{\mathrm{w}}$ is the liquid water density, $r_{3}$ is the mean volume droplet radius and $M_{3}$ is the third moment of the droplet spectrum.

From these two basic relationships, Twomey thus concluded that, in vertically uniform clouds, $\tau$ should scale like $N^{1 / 3}$ :

$\tau=\pi Q_{\mathrm{ext}} M_{2} H=\pi Q_{\mathrm{ext}} N^{1 / 3} M_{3}^{2 / 3} H=A(\mathrm{NH})^{1 / 3} W^{2 / 3}$,

where $A=\frac{\pi Q_{\mathrm{ext}}}{\left(4 / 3 \pi \rho_{\mathrm{w}}\right)^{2 / 3}}$.

Various authors, starting with Bower and Choularton (1992), however, noticed that this expression is only valid for a monodispersed (Dirac function) droplet spectrum where $r_{2}=r_{3}$, while in actual spectra, the spectrum width results in a small bias between the mean surface and mean volume radii. Martin et al. (1994) proposed to account for this bias using a correction factor $k$ that expresses as:

$k=\left(\frac{r_{3}}{r_{\mathrm{e}}}\right)^{3}=\left(\frac{r_{2}}{r_{3}}\right)^{6}$

where $r_{\mathrm{e}}$ is the droplet effective radius. It follows that: $M_{2}=$ $(k N)^{1 / 3} M_{3}^{2 / 3}$ and Eq. (3) becomes :

$\tau=A(k N H)^{1 / 3} W^{2 / 3}=\frac{3}{2 \rho_{\mathrm{w}}} \frac{W}{r_{\mathrm{e}}}$.

In situ measurements, however, attest that convective clouds are vertically stratified (Warner, 1969; Pawlowska and Brenguier, 2000). More precisely in an adiabatic cloud, the liquid water content increases almost linearly with height above cloud base, as $q_{\mathrm{c}}(h)=C_{\mathrm{w}} h$, where the condensation rate $C_{\mathrm{w}}$ depends on pressure and temperature at the cloud base (Brenguier, 1991) while CDNC remains constant after CCN activation. In this case Eq. (3) translates into:

$\tau=A^{\prime}(k N)^{1 / 3} W^{5 / 6}$,

where $A^{\prime}=\frac{3}{5} \frac{2^{5 / 6}}{C_{\mathrm{w}}^{1 / 6}} A$.

If the $k$ coefficient is constant, $\tau$ still scales with $N^{1 / 3}$, as postulated by Twomey. However, Martin et al. (1994) examined droplet spectra and aerosol properties measured during field experiments and found that $k$ varies from $0.67 \pm 0.07$ in continental air masses to $0.80 \pm 0.07$ in the marine ones. It follows that the Twomey effect might be slightly attenuated, with an optical thickness increasing like $(k N)^{1 / 3}$, while $k$ decreases when $N$ increases. This relationship between the $k$ factor and CDNC received additional support from observational field programs (Pawlowska and Brenguier, 2000; Hudson and Yum, 2001; McFarquhar and Heymsfield, 2001).

Subsequent papers tried to connect the $k$ correction factor to CDNC via the droplet spectrum relative dispersion, in order to quantify the attenuation of the Twomey effect (Liu et al., 2008, and references therein). This was even referred to as a "warming effect" (Liu and Daum, 2002), something of a misnomer, since an increase of the droplet concentration still leads to an increase of the light extinction, hence a higher optical thickness at constant LWP. More precisely, the argument was that the $k$ factor decrease with increasing CDNC leads to a "less than expected" cooling. Finally, this relationship was recently implemented in climate models (Jones et al., 2001; Peng and Lohmann, 2003; Rotstayn and Liu, 2003; Chen et al., 2010), with different $k$ values for pristine and polluted environments. It is thus timely to revisit a large data set of different cloud types to precisely quantify this potential mitigation of the Twomey effect. 


\section{The data sets}

\subsection{Field experiments}

Five data sets are revisited in this paper: two experiments were dedicated to shallow cumuli (SCMS and RICO), two were focused on marine stratocumulus clouds (ACE-2 and DYCOMS-II). During the fifth one (EUCAARI) both cumuli and stratocumuli were examined. The five field experiments and the diverse sampling strategies are briefly described hereafter. Table 1 reports for each experiment the list of the flights analyzed in this study and the mean cloud droplet number concentration values $\langle N\rangle$ are given in Table 4 .

The Small Cumulus Microphysics Study (SCMS) was conducted in Florida in July and August 1995 to investigate precipitation initiation in cumulus clouds (Knight and Miller, 1998). Three instrumented aircraft, the University of Wyoming King-Air, the National Center for Atmospheric Research (NCAR) C130 and the Météo-France Merlin-IV performed coordinated penetrations through isolated cumuli over the Cape Kennedy space centre, while the NCAR CP2 radar was sampling the same clouds with a high repetition rate (RHI scanning) (Göke et al., 2007). The clouds selected by the radar were sampled by the three aircraft at different levels from cloud base to the top. The eleven SCMS cases were sampled between 22 July and 12 August 1995. The data are from the Fast-FSSP on board the NCAR C130 on 22 and 24 July and on board the Météo-France Merlin-IV for the 9 following cases. The aircraft performed series of cloud traverses at various levels from the base to the top. The mean droplet concentration varies from 120 to $329 \mathrm{~cm}^{-3}$, depending on the air-mass origin, with pristine conditions when the airflow was from the ocean, and more polluted ones when wind was blowing from the continent (Hudson and Yum, 2001).

The CLOUDY-COLUMN element of the second Aerosol Characterization Experiment (ACE-2) was dedicated to marine stratocumulus clouds North of the Canary Islands, in June and July 1997, to examine the impact of anthropogenic pollution on cloud radiative properties (Brenguier et al., 2000a). Among the five aircraft participating to the project, the Météo-France Merlin-IV performed series of ascents and descents throughout the cloud layer and documented 8 cases with diverse levels of pollution, from very pristine oceanic air to polluted air masses originating from Europe (Brenguier et al., 2000b). Stratocumulus clouds were sampled over a $4 \mathrm{~h}$ period around local noon, with series of ascents and descents from below cloud base to above cloud top (Fig. 1 in Pawlowska and Brenguier, 2000). Different aerosol backgrounds were documented from very pristine marine air, with droplet concentrations of the order of $45 \mathrm{~cm}^{-3}$, to slightly polluted ones in air masses originating from Europe, with peak droplet concentrations up to $400 \mathrm{~cm}^{-3}$, and mean values up to $185 \mathrm{~cm}^{-3}$.
The second Dynamics and Chemistry of Marine Stratocumulus (DYCOMS-II) experiment was held of the coast of California in July 2001 with the NCAR C130 (Stevens et al., 2003). Most of the flights were performed at night to examine the nocturnal evolution of the cloud layer. The DYCOMS-II flights were series of large circles $(60 \mathrm{~km}$ in diameter) moving slowly with the boundary layer wind for a Lagrangian description of the layer, except for flights 09 (see Fig. S1 in the Supplement to Stevens et al., 2003). The NCAR C-130 performed constant level legs from the free troposphere to below the cloud base, with a few series of ascents and descents through the cloud layer. Only these latter soundings are used here.

The Rain In Cumulus over the Ocean (RICO) field study was focused on marine fair weather cumuli, East of the Antigua Island in the Caribbean from December 2004 to January 2005 (Rauber et al., 2007). Among the three aircraft participating to the project, the NCAR C130 conducted semirandom cloud penetrations at fixed altitude for periods of 30-60 min. The trade-wind cumulus sampled during the six RICO flights analyzed in this study exhibit very low droplet concentration with mean values ranging from 28 to $58 \mathrm{~cm}^{-3}$ but noticeable differences in their vertical development with depth from $400 \mathrm{~m}$ to $2.5 \mathrm{~km}$.

EUCAARI is a European project for aerosol impacts on health and climate (Kulmala et al., 2009). During the IMPACT field experiment that took place in the Netherlands in May 2008, the SAFIRE (Service des Avions Français Instrumentés pour la Recherche en Environnement) ATR-42 sampled diverse types of clouds over the Netherlands (isolated cumuli) and the North Sea (marine stratocumulus layer). From the EUCAARI data base, flights as 49 and 50 illustrate the properties of isolated cumuli sampled over land during a pollution event, with CDNC mean values of the order of $450 \mathrm{~cm}^{-3}$ and peak values up to $2000 \mathrm{~cm}^{-3}$. The cloud sampling was series of horizontal cloud traverses from base to top as in SCMS and RICO. The two other flights (as51 and 52) are a morning and an afternoon flight in a marine stratocumulus layer over the North Sea in a very pristine environment, hence low mean CDNC values of the order of 70 to $100 \mathrm{~cm}^{-3}$. The cloud sampling was made of series of ascents and descents as in ACE2 but along a straight line of about $120 \mathrm{~km}$ long.

\subsection{Measurements of the droplet size distribution}

The data analyzed here are from the Météo-France MerlinIV, the NCAR C130 and the SAFIRE ATR-42. A comprehensive suite of microphysical instruments (Droplet spectrometers, hot wire, PVM-100A) was operated on each aircraft. They have been carefully inter-calibrated for each campaign (Burnet and Brenguier, 1999, 2002). The data examined here are from droplet spectrometers, either the standard Particle Measuring Systems, Inc. (PMS) FSSP-100 with 15 size classes, the SPP-100, an electronically upgraded version 
Table 1. List of flights analysed here with the project name, the campaign location, the aircraft used, the type of sampled clouds and the FSSP versions that were operated.

\begin{tabular}{|c|c|c|c|c|c|c|c|c|}
\hline Project & Location & Aircraft & Date & Flight & Cloud type & FSSP-100 & SPP-100 & Fast-FSSP \\
\hline \multirow{11}{*}{ SCMS } & \multirow[t]{11}{*}{ Florida } & C-130 & $22 / 07 / 95$ & RF04 & $\mathrm{Cu}$ & $\mathrm{x}$ & & $\mathrm{x}$ \\
\hline & & C-130 & $24 / 07 / 95$ & RF05 & $\mathrm{Cu}$ & $\mathrm{x}$ & & $\mathrm{x}$ \\
\hline & & M-IV & $04 / 08 / 95$ & me05 & $\mathrm{Cu}$ & $\mathrm{x}$ & & $\mathrm{x}$ \\
\hline & & M-IV & $05 / 08 / 95$ & me06 & $\mathrm{Cu}$ & $\mathrm{x}$ & & $\mathrm{x}$ \\
\hline & & M-IV & 06/08/95 & me07 & $\mathrm{Cu}$ & $\mathrm{x}$ & & $\mathrm{x}$ \\
\hline & & M-IV & $07 / 08 / 95$ & me08 & $\mathrm{Cu}$ & $\mathrm{x}$ & & $\mathrm{x}$ \\
\hline & & M-IV & 08/08/95 & me09 & $\mathrm{Cu}$ & $\mathrm{x}$ & & $\mathrm{x}$ \\
\hline & & M-IV & 09/08/95 & me10 & $\mathrm{Cu}$ & $\mathrm{x}$ & & $\mathrm{x}$ \\
\hline & & M-IV & $10 / 08 / 95$ & me11 & $\mathrm{Cu}$ & $\mathrm{x}$ & & $\mathrm{x}$ \\
\hline & & M-IV & $11 / 08 / 95$ & me12 & $\mathrm{Cu}$ & $\mathrm{x}$ & & $\mathrm{x}$ \\
\hline & & M-IV & $12 / 08 / 95$ & me13 & $\mathrm{Cu}$ & $\mathrm{x}$ & & $\mathrm{x}$ \\
\hline \multirow{8}{*}{ ACE2 } & \multirow{8}{*}{ Canary islands } & M-IV & $25 / 06 / 97$ & me20 & $\mathrm{Sc}$ & & & $\mathrm{x}$ \\
\hline & & M-IV & $26 / 06 / 97$ & me21 & $\mathrm{Sc}$ & & & $\mathrm{x}$ \\
\hline & & M-IV & 08/07/97 & me28 & $\mathrm{Sc}$ & & & $\mathrm{x}$ \\
\hline & & M-IV & 09/07/97 & me30 & $\mathrm{Sc}$ & & & $\mathrm{x}$ \\
\hline & & M-IV & $16 / 07 / 97$ & me31 & $\mathrm{Sc}$ & & & $\mathrm{x}$ \\
\hline & & M-IV & $17 / 07 / 97$ & me33 & $\mathrm{Sc}$ & & & $\mathrm{x}$ \\
\hline & & M-IV & $18 / 07 / 97$ & me34 & $\mathrm{Sc}$ & & & $\mathrm{x}$ \\
\hline & & M-IV & $19 / 07 / 97$ & me35 & $\mathrm{Sc}$ & & & $\mathrm{x}$ \\
\hline \multirow[t]{4}{*}{ DYCOMS-II } & \multirow[t]{4}{*}{ northeast Pacific } & C-130 & $13 / 07 / 01$ & RF03 & $\mathrm{Sc}$ & & $\mathrm{x}$ & $\mathrm{x}$ \\
\hline & & C-130 & $24 / 07 / 01$ & RF07 & $\mathrm{Sc}$ & & $\mathrm{x}$ & $\mathrm{x}$ \\
\hline & & C-130 & $25 / 07 / 01$ & RF08 & $\mathrm{Sc}$ & & $\mathrm{x}$ & $\mathrm{x}$ \\
\hline & & C-130 & $27 / 07 / 01$ & RF09 & $\mathrm{Sc}$ & & $\mathrm{x}$ & $\mathrm{x}$ \\
\hline \multirow[t]{6}{*}{ RICO } & \multirow[t]{6}{*}{ Caribbean } & C-130 & $16 / 12 / 04$ & RF06 & $\mathrm{Cu}$ & & $\mathrm{x}$ & $\mathrm{x}$ \\
\hline & & C-130 & $17 / 12 / 04$ & RF07 & $\mathrm{Cu}$ & & $\mathrm{x}$ & $\mathrm{x}$ \\
\hline & & C-130 & $19 / 12 / 04$ & RF08 & $\mathrm{Cu}$ & & $\mathrm{x}$ & $\mathrm{x}$ \\
\hline & & C-130 & $20 / 12 / 04$ & RF09 & $\mathrm{Cu}$ & & $\mathrm{x}$ & $\mathrm{x}$ \\
\hline & & C-130 & $07 / 01 / 05$ & RF11 & $\mathrm{Cu}$ & & $\mathrm{x}$ & $\mathrm{x}$ \\
\hline & & C-130 & $11 / 01 / 05$ & RF12 & $\mathrm{Cu}$ & & $\mathrm{x}$ & $\mathrm{x}$ \\
\hline \multirow[t]{4}{*}{ EUCAARI } & \multirow{2}{*}{ The Netherlands } & ATR-42 & $13 / 05 / 08$ & as 49 & $\mathrm{Cu}$ & $\mathrm{x}$ & & $\mathrm{x}$ \\
\hline & & ATR-42 & $14 / 05 / 08$ & as 50 & $\mathrm{Cu}$ & $\mathrm{x}$ & & $\mathrm{x}$ \\
\hline & \multirow[t]{2}{*}{ North Sea } & ATR-42 & $15 / 05 / 08$ & as51 & $\mathrm{Sc}$ & $\mathrm{x}$ & & $\mathrm{x}$ \\
\hline & & ATR-42 & $15 / 05 / 08$ & as52 & $\mathrm{Sc}$ & $\mathrm{x}$ & & $\mathrm{x}$ \\
\hline
\end{tabular}

of this instrument from Droplet Measurement Technologies (DMT) with 40 size classes, and the Fast-FSSP with 255 size classes. Optical Array Probes (OAP) measurements are also analysed to extend the range of the droplet spectrometers to the drizzle sizes.

Very detailed descriptions of the FSSP-100 are already available in the literature (Dye and Baumgardner, 1984; Baumgardner et al., 1985; Brenguier, 1989). The FSSP-100 was operated with no delay to reduce over-counting in the first size class $(2-5 \mu \mathrm{m}$ in diameter).

The Fast-FSSP is a modified version of the FSSP-100 with new electronics that measures for each detection, the pulse amplitude, pulse duration and inter-arrival time from the previous detection with a resolution of $1 / 16 \mu$ s, and a flag that indicates if the particle crosses the beam inside, outside, or at the limit of the efficient beam sampling section (Brenguier et al., 1998). The Fast-FSSP acquisition system records these four parameters for each detection. The full set of 255 size classes is not usable for spectra measurements because the relationship between the measured scattered light intensity (Mie theory) and the droplet diameter is not monotonic. This high spectral resolution, however, is used to detect peaks that result from the ambiguities of the Mie response, hence providing an absolute calibration of the probe for each flight (Sect. 2d in Brenguier et al., 1998). Measurement of CDNC is also greatly improved because losses due to coincidence of droplets in the detection beam are corrected using three independent techniques based on particle counting, statistics of the pulse duration and of the droplet inter-arrival times (Brenguier et al., 1994).

Table 1 indicates for each flight the aircraft type and the FSSP versions that were operated. 
a) $\mathrm{SCMS}$

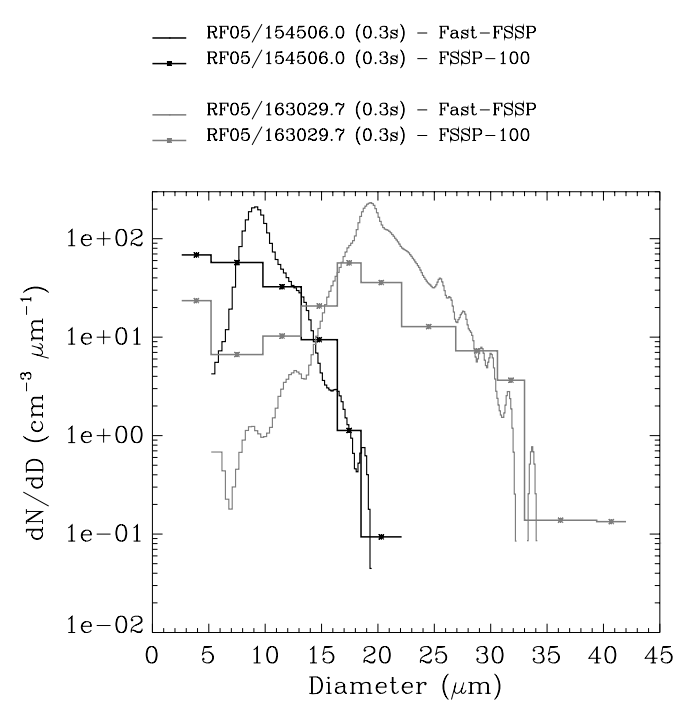

b) DYCOMS-II
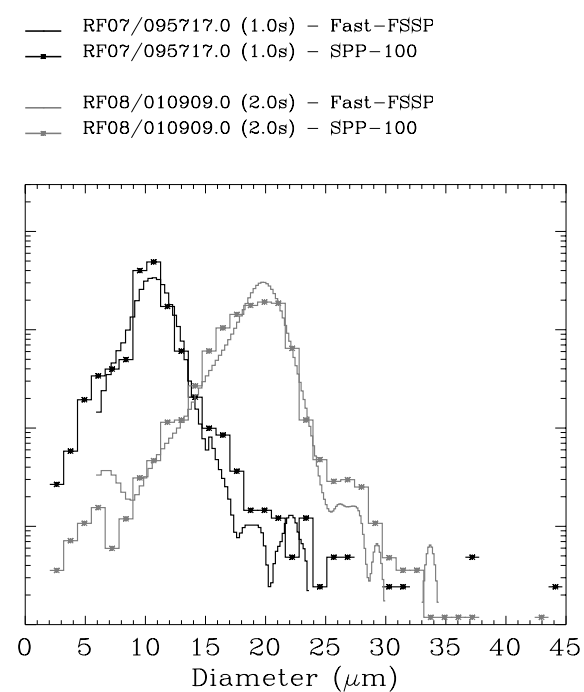

Fig. 1. Droplet size distributions as measured with (a) the FSSP-100 and the Fast-FSSP during SCMS and (b) the SPP-100 and the Fast-FSSP during DYCOMS-II.

Table 2. Coefficient $k$ values and ratio of the $k$ coefficient derived from the FSSP-100 or the SPP-100 to the value derived from the Fast-FSSP for the four droplet spectra shown in Fig. 1. Data from the FSSP-100 and the SPP-100 are processed over the full range and after removal of the first classes. The corresponding diameter ranges are indicated for each case.

\begin{tabular}{|c|c|c|c|c|c|c|c|}
\hline \multirow[t]{3}{*}{ Case } & \multicolumn{5}{|c|}{$k$} & \multicolumn{2}{|c|}{ ratio } \\
\hline & \multirow[b]{2}{*}{ Fast-FSSP } & \multicolumn{2}{|c|}{ FSSP-100 } & \multicolumn{2}{|c|}{ SPP-100 } & \multirow[b]{2}{*}{ Full } & \multirow[b]{2}{*}{ Reduced } \\
\hline & & Full & Reduced & Full & Reduced & & \\
\hline (a) SCMS diameter range $(\mu \mathrm{m})$ & {$[5.2-38.4]$} & [2.6-52] & {$[5.2-52]$} & & & & \\
\hline RF05 - 154506.0 & 0.900 & 0.656 & 0.799 & & & 0.729 & 0.828 \\
\hline RF05 - 163029.7 & 0.932 & 0.743 & 0.820 & & & 0.797 & 0.880 \\
\hline (b) DYCOMS-II diameter range $(\mu \mathrm{m})$ & [5.9-43.8] & & & [2-47] & {$[5.5-47]$} & & \\
\hline RF07 - 095717.0 & 0.924 & & & 0.861 & 0.876 & 0.932 & 0.948 \\
\hline RF08 - 010909.0 & 0.956 & & & 0.942 & 0.944 & 0.985 & 0.988 \\
\hline
\end{tabular}

\section{Results}

The objective of the data analysis is to determine quantitatively the relationship between the LWP and the optical thickness of the cloud layers. As derived in Sect. 2 above (Eqs. 5 and 6), this relationship involves the $k$ coefficient that relates the mean droplet volume radius of the droplet size distribution for the calculation of LWP, to the mean surface radius, for the calculation of optical thickness. Indeed, Eqs. (5) and (6) show that, once LWP and CDNC are predicted in a GCM grid, the optical thickness can be derived after multiplying CDNC by the $k$ coefficient. In the following sub-sections, various sources of biases will be examined that impact the calculation of the $k$ correction factor.

\subsection{Instrumental biases}

Figure 1 shows examples of measured droplet size distributions in clouds sampled by the NCAR C130. In Fig. 1a, the two samples are from the SCMS flight RF05 with both the PMS-FSSP-100 and the Fast-FSSP. In Fig. 1b, the samples are from the DYCOMS-II RF07 and 08, with the DMT SPP-100 and the Fast-FSSP. Table 2 summarizes the estimations of the $k$ coefficient for these spectra. For SCMS, the FSSP-100 is processed with the 15 size classes (from 2.6 to $52 \mu \mathrm{m}$ in diameter), and without the first class (5.2 to $52 \mu \mathrm{m})$ to replicate the Fast-FSSP diameter range (5.2 to $38.4 \mu \mathrm{m})$. During DYCOMS-II, the Fast-FSSP range was (5.9 to $43.8 \mu \mathrm{m}$ ) and similarly the SPP-100 data are processed 
Table 3. Same as Table 2 but for the mean values over all cloudy samples of SCMS RF04 and 05 and DYCOMS-II RF07 and 08.

\begin{tabular}{l|l|ll|ll|l|l}
\hline Case & \multicolumn{5}{|c|}{$\langle k\rangle$} & \multicolumn{2}{c|}{$\langle$ ratio $\rangle$} \\
\hline & & \multicolumn{2}{|c|}{ FSSP-100 } & \multicolumn{2}{c|}{ SPP-100 } & \\
\cline { 3 - 7 } & Fast-FSSP & Full & Reduced & Full & Reduced & Full & Reduced \\
\hline SCMS & 0.828 & 0.658 & 0.769 & & & 0.797 & 0.933 \\
DYCOMS-II & 0.904 & & & 0.867 & 0.885 & 0.947 & 0.977 \\
\hline
\end{tabular}

ones with the full range ( 2 to $47 \mu \mathrm{m}$ ), and second without the first 4 classes ( 5.5 to $47 \mu \mathrm{m}$ ).

Figure 1a reveals that the FSSP-100 overestimates the droplet counts in the first two or three size classes and partly smoothes out the mode of the size distribution. This feature has commonly been attributed (Burnet and Brenguier, 2002) to the real-time system of the FSSP-100 that selects, among all counted droplets, those crossing the detection beam in its central section (depth-of-field and velocity reject). The FastFSSP uses a different system referred to as the slit selection (Brenguier et al., 1998). Consequently, the derived $k$ values are underestimated by the FSSP-100. Removing the first size classes partly compensates the discrepancy. In contrast, Fig. $1 b$ shows that the 40 size classes of the SPP- 100 are sufficient to accurately characterize the spectral shape, hence providing $k$ estimations very similar to the ones derived with the Fast-FSSP, regardless of the size range.

Table 3 summarizes the comparison of the mean $k$ values, $\langle k\rangle$, over all cloudy samples of the flight with the three instruments. The average of the ratio of the $k$ values derived from FSSP-100 or SPP-100 spectra to the values derived using the Fast-FSSP are reported for SCMS RF04 and 05 with the NCAR FSSP-100, full range and after removal of the first class, and for the DYCOMS-II RF07 and 08, with the NCAR SPP-100, full range and after removal of the first 4 classes. As suggested by the two examples shown in Fig. 1, the $k$ values derived using a FSSP-100 are significantly underestimated ( $80 \%$ of the Fast-FSSP derived values) due to the poor accuracy of the first size class. The discrepancy is significantly reduced $(93 \%)$ when the spurious counts of the first class are not accounted for. Values derived with the full range of the SPP-100 are within $95 \%$ of the ones derived with the Fast-FSSP and up to $98 \%$ when the first 4 classes are not accounted for.

In summary, the original FSSP-100 probe, with its coarse size resolution, is not well suited for measurements of the droplet spectrum width, or any related parameter such as the $k$ factor. Moreover, its real-time droplet selection procedure produces spurious counts in the first class that significantly affect the calculation of the $k$ factor, especially when the mean volume diameter is small. Since high concentration polluted clouds have lower droplet diameters at similar LWC than the low concentration pristine ones, the bias in $k$ towards lower values that is generated by this instrumental artefact is greater in polluted clouds. This comparison also shows the impact of limiting the $k$ evaluation to droplet larger than $5.5 \mu \mathrm{m}$ with the Fast-FSSP in SCMS and DYCOMS-II. Indeed, the difference between the mean $\langle k\rangle$ value derived with the SPP-100 full range [2-47 $\mu \mathrm{m}]$ and the one derived using the reduced range $[5.5-47 \mu \mathrm{m}]$ is 0.018 , i.e. a relative error of $2.1 \%$.

One can also notice that the upper limit of the size range varies significantly between probes, $38.4 \mu \mathrm{m}$ and $43.8 \mu \mathrm{m}$ for the Fast-FSSP during SCMS and DYCOMS-II, respectively, $52 \mu \mathrm{m}$ for the FSSP-100 during SCMS and $47 \mu \mathrm{m}$ for the SPP-100 during DYCOMS-II. Sensitivity tests, however, reveal that the impact of these differences on the mean $\langle k\rangle$ values are negligible, less than $0.5 \%$.

\subsection{The contribution of drizzle particles}

In principle, radiative transfer calculations in GCMs should be performed for each model column with all condensed particles, droplets, drizzle drops and precipitating drops. It is thus meaningful to examine how sensitive are the estimations of the $k$ factor to the presence of drizzle drops in clouds. The impact of precipitation drops is not considered here since the sampled cloud systems were only slightly drizzling. Indeed, the most drizzling cases, sampled during the DYCOMS-II campaign, exhibit 9th deciles of drizzle water content of 0.055 and $0.047 \mathrm{~g} \mathrm{~m}^{-3}$ for flights RF07 and RF08, respectively. During ACE-2 the Merlin-IV was equipped with a PMS-OAP-200X (diameter range from 35 to $310 \mu \mathrm{m}$ with a resolution of $20 \mu \mathrm{m}$ ), and during DYCOMS-II, the NCARC130 was equipped with a PMS-OAP- 260X (45 to $635 \mu \mathrm{m}$, with a resolution of $10 \mu \mathrm{m}$ ). These instruments are combined with droplet spectrometers to provide a full spectrum of droplets and drizzle drops. In Fig. 2, the $\langle k\rangle$ values derived using the droplet probe only are compared to those derived using the extended spectra with an upper limit of $55 \mu \mathrm{m}$, $75 \mu \mathrm{m}$, and the whole available range. With a range extended to $55 \mu \mathrm{m}$ (Fig. 2a), the $\langle k\rangle$ estimations are reduced by less than $2 \%$ and the average for the 11 ACE- 2 and DYCOMS-II flights decreases from 0.788 to 0.780 that is about $1 \%$. With a range extended to $75 \mu \mathrm{m}$ (Fig. 2b), the reduction is slightly greater, less than $4 \%$ and less than $2 \%$ on average for the 

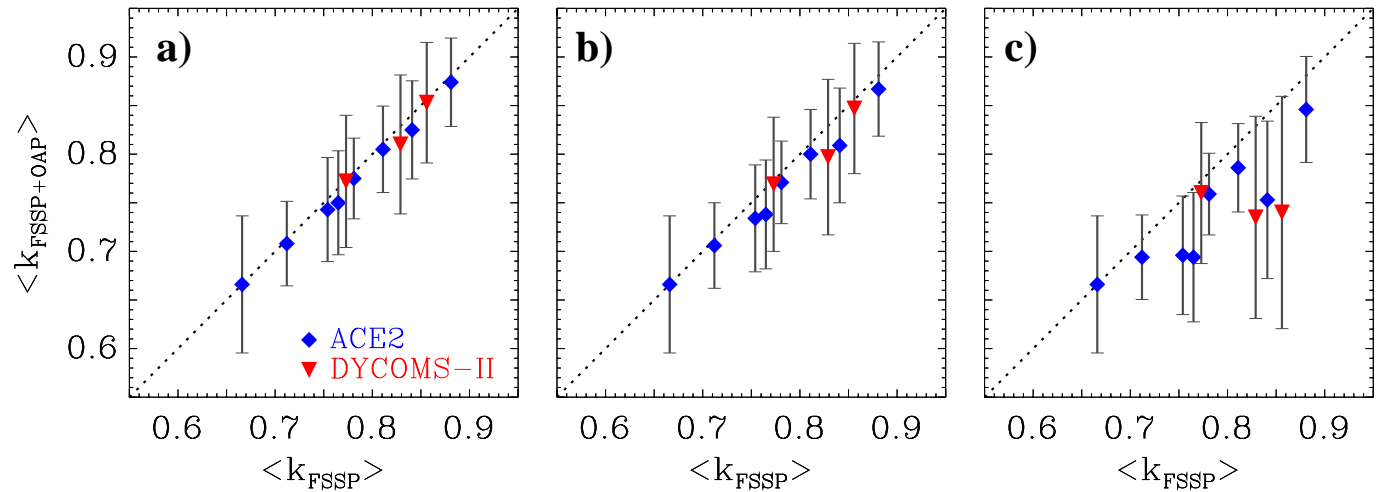

Fig. 2. Scatterplot of the mean flight $k$ values as derived using the size spectra extended with the drizzle probe with an upper limit set to (a) $55 \mu \mathrm{m}$, (b) $75 \mu \mathrm{m}$, and (c) the nominal upper diameter range of the probe $(310 \mu \mathrm{m}$ for the OAP-200X in ACE-2, and $635 \mu \mathrm{m}$ for the OAP-260X in DYCOMS-II), against the values derived using the droplet probe only. Error bars correspond to one standard deviation.

11 flights (from 0.788 to 0.773 ). Finally, with the full OAP ranges (Fig. 2c), the $\langle k\rangle$ value drops by $13 \%$ for the most drizzling case in DYCOMS-II (RF07). On average $\langle k\rangle$ is reduced to 0.739 , that is about $6 \%$ lower than the estimation derived using droplet probes only. Interestingly, $\langle k\rangle$ is affected by a few very small $k$ values (less than 0.5 and down to almost 0 ) that correspond to $1 \mathrm{~Hz}$ samples with very small droplets and a few drizzle drops. This is attested by plotting the $1 \mathrm{~Hz}$ sample values of the ratio of the droplet and drizzle to the droplets only $k$ factor as a function of the ratio of the drizzle to droplet water contents. The $k$ ratio decreases down to 0.2 when the drizzle to droplet water content ratio exceeds unity, and the results precisely replicate the features shown in Fig. 8 of Wood (2000). Such samples, with their low extinction and water content in fact do not contribute to the cloud albedo, although they impact the mean $k$ value. This issue will be further addressed in Sect. 4.6. Finally, one can notice that the $\langle k\rangle$ values are reduced in the most precipitating clouds, i.e. the marine ones, an effect that partly counteracts the increase of the $k$ factor in marine clouds suggested by Martin et al. (1994).

Including drizzle particles in the $\langle k\rangle$ estimations, however, is not consistent with the use of this correction factor in GCM radiative transfer calculations. Indeed, radiative transfer in GCM is based on the column integrated cloud water mixing ratio and precipitating particles are not accounted for. The separation between cloud water and precipitation, however, varies between models, from $50 \mu \mathrm{m}$ to about $80 \mu \mathrm{m}$ (Geoffroy et al., 2010). Figure 2 demonstrates that, within this range, the estimations of the $k$ coefficient vary by less than $2 \%$ on average. In the following sections, all the calculations are therefore based on either the Fast-FSSP or the SPP-100 with their specific ranges.

\subsection{Intra-cloud variability of the microphysics}

In real clouds, droplet spectra are highly variable in space and time. This is illustrated in Fig. 3 with data collected in a cumulus cloud during the SCMS flight me11 (Cell A in Burnet and Brenguier, 2010). During this campaign, cloud sampling started in active convective turrets and lasted until they were collapsing. Droplet spectra measured with the Fast-FSSP were processed at $10 \mathrm{~Hz}$ (droplet counts cumulated along $\sim 10 \mathrm{~m}$ of flight). Such a high sampling rate is necessary in isolated cumulus because cloud traverses are short, so that $100 \mathrm{~m}$ samples are often heterogeneous with intertwined clear air filaments, and cumulating droplet counts on too long and heterogeneous samples introduces noticeable biases in the calculation of CDNC.

Each cloudy sample is characterized by its $k$ value, where $k=M_{2}^{3} / N M_{3}^{2}$, as a function of $N$ (upper panel) and of the ratio of the liquid water content $q_{\mathrm{c}}$ to the adiabatic value $q_{\mathrm{cad}}$ at that level (lower panel). The LWC adiabatic fraction $q_{\mathrm{c}} / q_{\mathrm{cad}}$ is used here as a proxy for the level of mixing between the cloud and its environment, from the cloud base to the observation level. The colours correspond to the six successive aircraft penetrations in this turret, and the penetration number is indicated above the $\mathrm{x}$-axis.

This figure reveals that the $k$ values decrease with decreasing $N$ and decreasing $q_{\mathrm{c}} / q_{\mathrm{cad}}$. As already noticed by Warner (1969), from droplets impacted on sooted glass slides, cloud samples affected by mixing with the environmental dry air exhibit broad, occasionally bimodal spectra, with numerous droplets smaller than the mode, hence a lower $k$ value than in the cloud core where droplet spectra are narrower. When averaged over each cloud traverse, this trend, illustrated by the mean $k$ value of each cloud penetration (larger dots) reflects the progressive impact of the mixing processes during the lifetime of the convective turret. 
Table 4. Summary of the data set with for each flight the mean and standard deviation $\sigma$ of CDNC $\langle N\rangle$ and $k$ values $\langle k\rangle$, the $k^{*}$ value, the ratio of $k^{*}$ to $\langle k\rangle$, the $N_{\text {act }}$ parameter, the ratio $N / N_{\text {act }}$, the mean LWC adiabatic fraction $\left\langle q_{\mathrm{c}} / q_{\mathrm{cad}}\right\rangle$ and the cumulated length of cloudy samples $L_{\mathrm{c}}$. The last line for each data set shows the mean values, except for the last column that shows the total length of cloudy samples. Fast-FSSP measurements are used for all flights except DYCOMS-II on 24, 25 and 27 July for which the SPP-100 is used.

\begin{tabular}{|c|c|c|c|c|c|c|c|c|}
\hline Date & $\langle N\rangle \pm \sigma\left(\mathrm{cm}^{-3}\right)$ & $\langle k\rangle \pm \sigma$ & $k^{*}$ & $k^{*} /\langle k\rangle$ & $N_{\text {act }}\left(\mathrm{cm}^{-3}\right)$ & $N / N_{\text {act }}$ & $\left\langle q_{\mathrm{c}} / q_{\mathrm{cad}}\right\rangle$ & $L_{\mathrm{c}}(\mathrm{km})$ \\
\hline \multicolumn{9}{|c|}{ SCMS (1995) } \\
\hline $22 / 07$ & $294 \pm 243$ & $0.825 \pm 0.060$ & 0.692 & 0.839 & 926 & 0.318 & 0.213 & 23.8 \\
\hline $24 / 07$ & $329 \pm 235$ & $0.830 \pm 0.069$ & 0.707 & 0.852 & 759 & 0.434 & 0.246 & 47.9 \\
\hline $04 / 08$ & $120 \pm 62$ & $0.811 \pm 0.085$ & 0.788 & 0.972 & 224 & 0.536 & 0.324 & 70.6 \\
\hline 05/08 & $121 \pm 60$ & $0.802 \pm 0.074$ & 0.801 & 0.999 & 218 & 0.555 & 0.321 & 49.7 \\
\hline 06/08 & $152 \pm 72$ & $0.867 \pm 0.071$ & 0.759 & 0.875 & 274 & 0.555 & 0.263 & 74.8 \\
\hline 07/08 & $225 \pm 175$ & $0.819 \pm 0.100$ & 0.703 & 0.858 & 683 & 0.329 & 0.259 & 56.0 \\
\hline 08/08 & $325 \pm 255$ & $0.817 \pm 0.052$ & 0.792 & 0.969 & 940 & 0.346 & 0.264 & 37.8 \\
\hline 09/08 & $186 \pm 123$ & $0.858 \pm 0.056$ & 0.805 & 0.938 & 447 & 0.416 & 0.447 & 26.7 \\
\hline $10 / 08$ & $129 \pm 82$ & $0.843 \pm 0.077$ & 0.744 & 0.883 & 250 & 0.516 & 0.344 & 46.5 \\
\hline $11 / 08$ & $194 \pm 118$ & $0.823 \pm 0.079$ & 0.739 & 0.898 & 424 & 0.458 & 0.288 & 36.5 \\
\hline $12 / 08$ & $312 \pm 185$ & $0.840 \pm 0.049$ & 0.754 & 0.898 & 670 & 0.466 & 0.400 & 19.8 \\
\hline mean & 217 & 0.831 & 0.753 & 0.907 & 529 & 0.448 & 0.306 & 490.1 \\
\hline \multicolumn{9}{|c|}{ ACE-2 (1997) } \\
\hline $25 / 06$ & $50 \pm 20$ & $0.841 \pm 0.094$ & 0.755 & 0.898 & 63 & 0.794 & 0.879 & 84.3 \\
\hline $26 / 06$ & $45 \pm 19$ & $0.881 \pm 0.085$ & 0.775 & 0.880 & 53 & 0.849 & 0.916 & 63.8 \\
\hline 08/07 & $172 \pm 55$ & $0.811 \pm 0.085$ & 0.779 & 0.961 & 212 & 0.811 & 0.833 & 41.7 \\
\hline $09 / 07$ & $185 \pm 74$ & $0.781 \pm 0.080$ & 0.752 & 0.963 & 258 & 0.717 & 0.828 & 45.2 \\
\hline $16 / 07$ & $107 \pm 44$ & $0.666 \pm 0.141$ & 0.612 & 0.919 & 117 & 0.915 & 0.829 & 39.6 \\
\hline $17 / 07$ & $104 \pm 34$ & $0.765 \pm 0.103$ & 0.712 & 0.931 & 120 & 0.867 & 0.809 & 50.2 \\
\hline $18 / 07$ & $161 \pm 54$ & $0.712 \pm 0.085$ & 0.656 & 0.921 & 173 & 0.931 & 0.984 & 31.0 \\
\hline $19 / 07$ & $127 \pm 58$ & $0.754 \pm 0.103$ & 0.685 & 0.909 & 132 & 0.962 & 0.882 & 74.7 \\
\hline mean & 119 & 0.776 & 0.716 & 0.923 & 141 & 0.856 & 0.870 & 431.2 \\
\hline \multicolumn{9}{|c|}{ DYCOMS-II (2001) } \\
\hline $13 / 07$ & $175 \pm 64$ & $0.883 \pm 0.102$ & 0.844 & 0.956 & 194 & 0.902 & 0.902 & 50.0 \\
\hline $24 / 07$ & $126 \pm 45$ & $0.856 \pm 0.121$ & 0.769 & 0.898 & 147 & 0.857 & 0.672 & 80.0 \\
\hline $25 / 07$ & $100 \pm 42$ & $0.829 \pm 0.120$ & 0.755 & 0.911 & 110 & 0.909 & 0.783 & 55.8 \\
\hline $27 / 07$ & $220 \pm 71$ & $0.773 \pm 0.133$ & 0.743 & 0.961 & 245 & 0.898 & 0.786 & 59.5 \\
\hline mean & 155 & 0.835 & 0.778 & 0.932 & 213 & 0.892 & 0.786 & 245.3 \\
\hline \multicolumn{9}{|c|}{ RICO (2004-05) } \\
\hline $16 / 12$ & $58 \pm 40$ & $0.833 \pm 0.102$ & 0.731 & 0.878 & 108 & 0.537 & 0.287 & 102.2 \\
\hline $17 / 12$ & $28 \pm 14$ & $0.779 \pm 0.117$ & 0.659 & 0.846 & 55 & 0.509 & 0.266 & 106.5 \\
\hline $19 / 12$ & $35 \pm 20$ & $0.781 \pm 0.120$ & 0.706 & 0.904 & 75 & 0.467 & 0.214 & 172.4 \\
\hline $20 / 12$ & $35 \pm 18$ & $0.791 \pm 0.097$ & 0.747 & 0.944 & 67 & 0.522 & 0.221 & 49.6 \\
\hline 07/01 & $39 \pm 25$ & $0.748 \pm 0.126$ & 0.617 & 0.825 & 93 & 0.419 & 0.167 & 87.4 \\
\hline $11 / 01$ & $45 \pm 25$ & $0.808 \pm 0.092$ & 0.762 & 0.943 & 87 & 0.517 & 0.268 & 84.1 \\
\hline mean & 40 & 0.790 & 0.704 & 0.890 & 81 & 0.495 & 0.237 & 602.2 \\
\hline \multicolumn{9}{|c|}{ EUCAARI (2008) } \\
\hline $13 / 05$ & $446 \pm 270$ & $0.795 \pm 0.044$ & 0.773 & 0.972 & 915 & 0.487 & 0.174 & 19.0 \\
\hline $14 / 05$ & $474 \pm 400$ & $0.780 \pm 0.061$ & 0.750 & 0.962 & 1437 & 0.330 & 0.236 & 34.8 \\
\hline mean & 460 & 0.788 & 0.762 & 0.967 & 1176 & 0.409 & 0.205 & 53.9 \\
\hline $15 / 05$ & $107 \pm 30$ & $0.814 \pm 0.067$ & 0.753 & 0.925 & 119 & 0.899 & 0.852 & 226.8 \\
\hline $15 / 05$ & $65 \pm 23$ & $0.797 \pm 0.088$ & 0.705 & 0.885 & 72 & 0.903 & 0.786 & 149.3 \\
\hline mean & 86 & 0.806 & 0.729 & 0.905 & 96 & 0.901 & 0.819 & 376.1 \\
\hline \multicolumn{8}{|c|}{ Total cumulated length of samples (km) } & 2198 \\
\hline
\end{tabular}



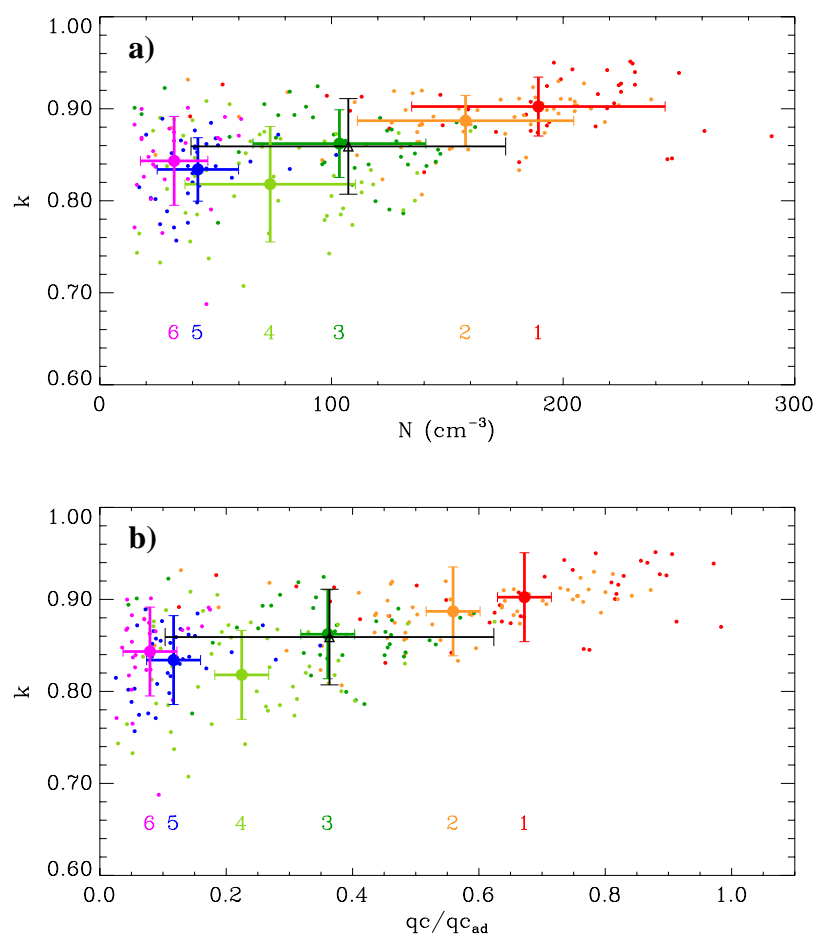

Fig. 3. Scatterplot of the $10 \mathrm{~Hz}$ sample $k$ factor values derived from Fast-FSSP data collected in a $\mathrm{Cu}$ during SCMS (points) as function of (a) the total droplet number concentration and (b) the LWC adiabatic fraction. Mean value is indicated for each of the six cloud traverses performed in this turret (colour dot) and for the whole data set (black triangle). Error bars correspond to one standard deviation.

\subsection{Inter-cloud variability of the microphysics}

The next step is therefore to examine if such features are also noticeable at the scale of the cloud systems. The 33 case studies listed in Table 1 are now analyzed concurrently. The results are summarized in Table 4. The cumulated length of cloudy samples is indicated in the last column. Note that data from stratocumulus layers (ACE-2, DYCOMS-II and EUCAARI as51 and 52) are processed at $1 \mathrm{~Hz}$ (about $100 \mathrm{~m}$ ), while the ones collected in cumulus clouds are processed at $10 \mathrm{~Hz}$ for the same reason as already mentioned in the previous subsection. The mean CDNC and $k$ values, $\langle N\rangle$ and $\langle k\rangle$ respectively, are given with the standard deviation of their frequency distributions for each flight.

Figure 4 shows, for the 33 case studies listed in Table 4, how $\langle k\rangle$ varies with the mean LWC adiabatic fraction $\left\langle q_{\mathrm{c}} / q_{\mathrm{cad}}\right\rangle$, where \langle\rangle is the average over all cloudy samples of a case study. The figure corroborates previous findings that dilution is more pronounced in $\mathrm{Cu}$ clouds than in Sc. It also reveals for cumulus clouds that the relationship between the $k$ ratio and the adiabatic fraction observed at the scale of a convective turret is still noticeable for the entire cloud systems, with $\langle k\rangle$ increasing from 0.748 to 0.858 while $\left\langle q_{\mathrm{c}} / q_{\mathrm{cad}}\right\rangle$ increases from 0.167 to 0.447 .

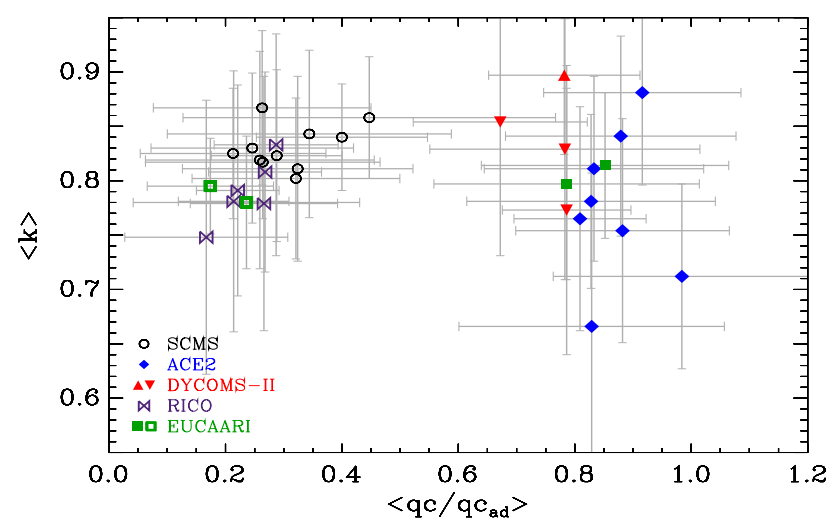

Fig. 4. Scatterplot of $\langle k\rangle$ values as function of the LWC adiabatic fraction. For the LWC adiabatic fraction, the difference between the 80th and the 20th percentile of the frequency distribution is used as the error bar instead of the standard deviation to represent the variability. Symbols depend on the project as indicated in the legend with open and solid symbols for $\mathrm{Cu}$ and $\mathrm{Sc}$ clouds, respectively. For DYCOMS-II pointing up triangle is for Fast-FSSP data and pointing down triangles are for SPP-100 data.

Surprisingly, some of the stratocumulus layers, that are characterized by higher values of the LWC adiabatic fraction, also exhibit lower values of the $k$ factor than the $\mathrm{Cu}$ ones, and even the opposite trend with decreasing $k$ values when the adiabatic fraction increases, although this trend is not statistically significant. In fact, entrainment-mixing processes are noticeably different in the two cloud types. Stratocumulus clouds develop in a moist boundary layer so that entrainment has little impact on cloud microphysics (Fig. 5 in Pawlowska and Brenguier, 2000), except at cloud top where the cloud is mixed with warmer and dryer air from the inversion layer above. In contrast, isolated cumuli grow in a drier free tropospheric environment so that LWC is progressively diluted by lateral entrainment. This fundamental difference explains why the LWC adiabatic fraction is lower in isolated cumuli than in stratocumulus layers. Moreover, cloud top entrainment in stratocumulus exhibits extreme inhomogeneous mixing features (Burnet and Brenguier, 2007), during which dilution of the LWC is mainly accounted for by a dilution of CDNC while droplet sizes are almost unaffected. In contrast, lateral entrainment in isolated cumuli shows more homogeneous like features. Considering the reduction of the $k$ factor when dilution increases, as shown in Fig. 3, one would expect $\mathrm{Cu}$ clouds to exhibit lower $k$ values than the stratocumulus ones. The impact of entrainment-mixing processes on the droplet spectral width and the $k$ factor in different cloud types thus deserves more examination.

These effects were accounted for by Martin et al. (1994) who mentioned that "when entrainment effects become important the relationship between re and $r_{v}$ breaks down and such data have been ignored in the analysis". Our objective, however, is to empirically derive a $k$ factor value for parame- 
a) SCMS - me9511

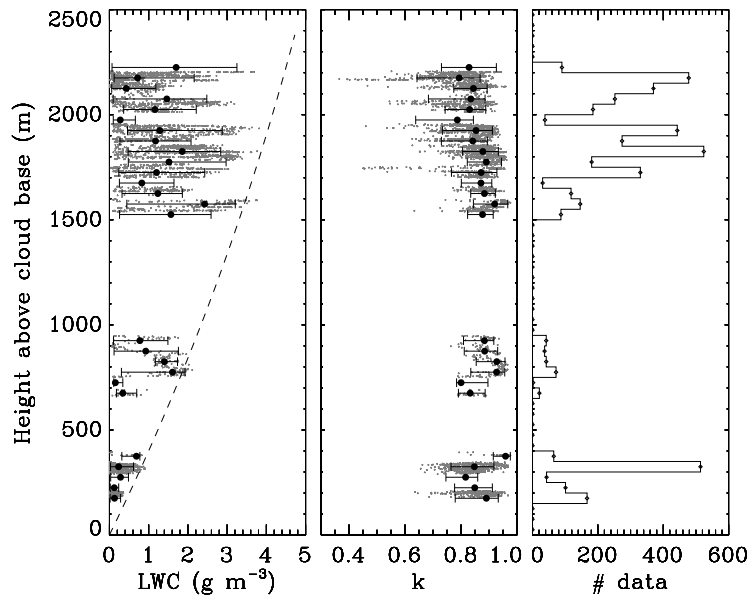

b) EUCAARI - as0851

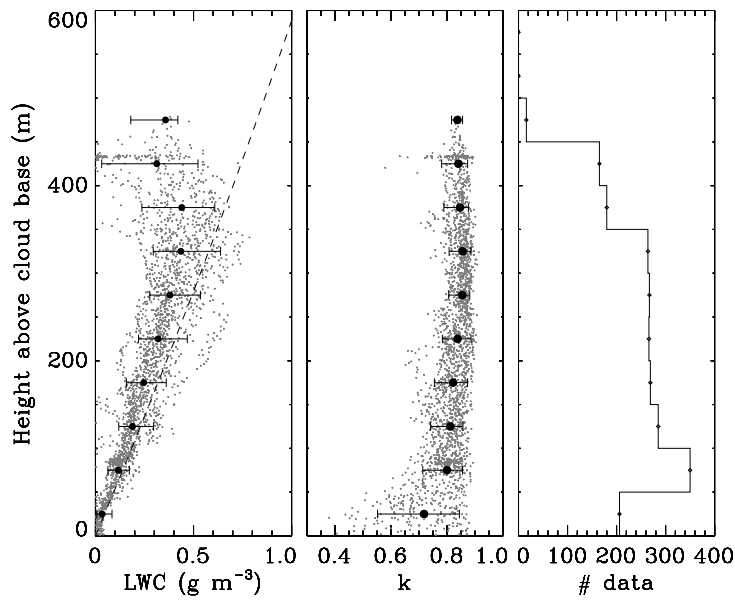

Fig. 5. Vertical profiles of LWC, the $k$ factor and the number of data points in each $50 \mathrm{~m}$ altitude interval above cloud base. For LWC and the $k$ factor, the mean value (black dot) and the 1st and 9th deciles of the frequency distribution (error bar) are superimposed to the data (grey points). The dashed line on the left panel corresponds to the adiabatic LWC profile.

terization of the aerosol indirect effect in climate models, i.e. a value that characterizes cloud systems as a whole, including both quasi-adiabatic and diluted cloud regions.

Dilution and droplet evaporation following entrainmentmixing is not the only source of variability for the $k$ coefficient. For instance, during the ACE2 me31 flight, two legs were flown $60 \mathrm{~km}$ apart, that exhibit quite different values of the $k$ factor, 0.74 and 0.61 , respectively. They also show noticeable differences in term of cloud thickness, with the lowest $k$ value for the thinnest cloud layer.

These observations highlight the importance of the sampling strategy when trying to characterize large scale properties of a cloud field for GCM parameterizations. Indeed, it is difficult with an aircraft to uniformly sample a field of isolated cumuli, from cloud base to cloud top, and from their early stage of growth to their dissipation, to derive cloud system representative values of vertically integrated physical parameters. Figure 5a shows an example of the SCMS data set, with the vertical profile of LWC, the $k$ factor and the number of data points in each $50 \mathrm{~m}$ altitude interval above cloud base. For LWC and the $k$ factor, the mean value and 1st and 9th deciles at each level are superimposed. This figure reveals that all levels above cloud base are not sampled uniformly, and that some levels exhibit a large variability of the LWC adiabatic fraction and of the $k$ factor.

From this point of view, the Sc clouds data set, during which all altitude levels were sampled with the same frequency during constant climbing rate ascents and descents, is much more suited. Figure $5 \mathrm{~b}$ illustrates this statement with the vertical profile of the $k$ factor for all the soundings of EUCAARI flight as51. The figure shows a large range of $k$ values at cloud base, extending from less than 0.4 to 0.90 , followed by a shrinking of the distributions with altitude and most of the values ranging between 0.80 and 0.90 .

Considering the importance of the intra-cloud variability, in space and time, and its impact on the cloud system values of the $k$ factor, we consider that the contrasting trends observed in Fig. 4 between $\mathrm{Cu}$ and $\mathrm{Sc}$ clouds are not significant as they are likely to reflect small differences in airborne sampling, with varying fractions of undiluted cores versus diluted cloud regions during each flight.

This variability of the microphysics is a serious obstacle to an experimental assessment of the first indirect effect. Indeed, Twomey adopted a global perspective when postulating that clouds of the post industrial era should have a higher albedo than similar clouds of the pre-industrial era. Therefore, "similar" here means similar liquid water path, similar morphology, similar life cycle and also similar level of mixing. As a proxy for the pre- and post-industrial eras, today observations focus on pristine and polluted cloud systems. To detect and quantify the aerosol indirect effect, beyond the intra-cloud variability of the microphysics is a challenge that raises methodological issues, as discussed in the following sections.

\subsection{Mean value of the $k$ factor}

The cloud system mean values of the $k$ factor are plotted in Fig. 6a and $\mathrm{b}$ as a function of the mean CDNC values for $\mathrm{Sc}$ and $\mathrm{Cu}$ cloud types, respectively. The error bars represent the standard deviation of the parameter frequency distributions. The red dashed line represent the average over all cases for each cloud type, with an orange bar for the standard deviation. The two values recommended by Martin et al. (1994) are indicated with dotted lines and vertical bar apart for the standard deviation.

There is no detectable trend of the mean $k$ value with the mean CDNC one in Sc clouds. The range of sounding average CDNC values in our data is, however, limited to $280 \mathrm{~cm}^{-3}$ while Martin et al. (1994) report a few values 
a) Stratocumulus cases

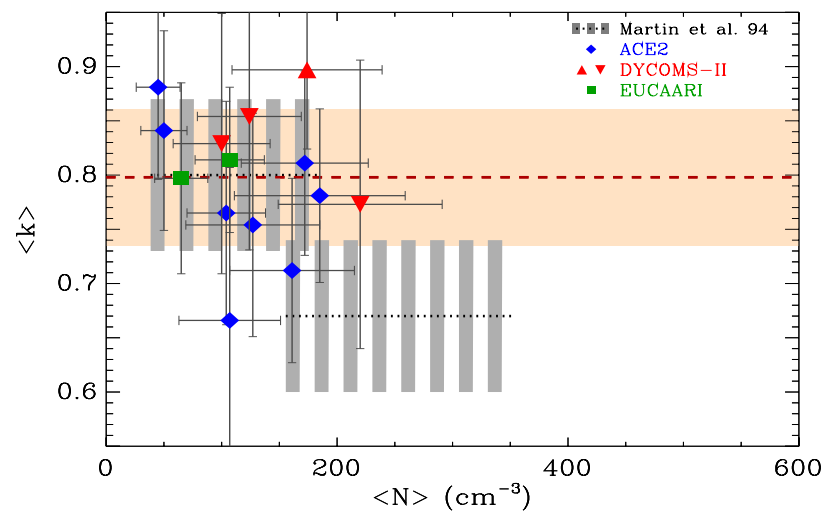

b) Cumulus cases

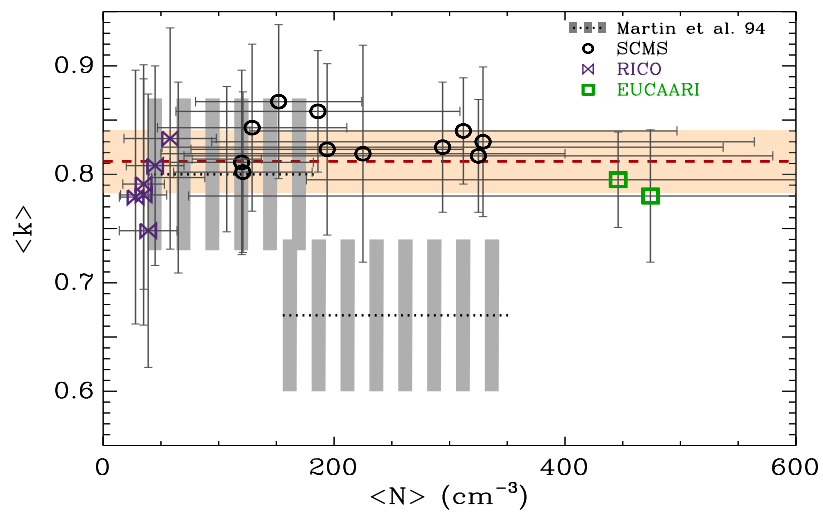

Fig. 6. Flight averaged $k$ factor as function of mean total droplet number concentration for the cases studies listed in Table 4, Sc clouds in (a) and $\mathrm{Cu}$ clouds in (b). The error bar corresponds to one standard deviation. The average of all the cases in each figure is indicated with a dashed line and a light orange bar for the standard deviation. The two dotted lines with grey bars apart are the values recommended by Martin et al. (1994).

up to $450 \mathrm{~cm}^{-3}$. Most of the ACE-2 cases in Fig. 6a show lower $\langle k\rangle$ values than the DYCOMS-II and the EUCAARI ones. We attribute this noticeable difference to the fact that the ACE-2 cloud layers were thinner and less solid than the others. Note also that from a microphysical point of view the four lowest $\langle k\rangle$ values correspond to the intermediate cases $(16,17,18$, and 19 July), as opposed to the greater values of the most pristine ( 25 and 26 June) and polluted ( 8 and 9 July) ones. For the $\mathrm{Cu}$ clouds (Fig. 6b), the range of $\mathrm{CDNC}$ values is broader with maximum mean values larger than $400 \mathrm{~cm}^{-3}$, but there is no detectable trend either. The average over the $\mathrm{Cu}$ cases, equal to $0.812 \pm 0.029$ is similar to the $\mathrm{Sc}$ average, equal to $0.798 \pm 0.063$, but the standard deviation is three times lower.

Remarkably, the average of all the 33 cases, $\mathrm{Sc}$ and $\mathrm{Cu}$ merged, equal to $0.807 \pm 0.047$ is very close to the value proposed by Martin et al. for the pristine cases: $0.80 \pm 0.07$.

\subsection{Local mean versus vertically integrated cloud properties}

In the previously published papers, as well as in the analysis above, the $k$ values were derived locally from the mean surface and mean volume droplet radii of each sample, i.e. from light extinction and liquid water content, while the Twomey hypothesis refers to optical thickness and LWP, i.e. to vertical integrals of these measured parameters. To approximate such vertical integrals with horizontal cloud traverses, it would be necessary to uniformly sample a cloud system from cloud base to cloud top. The cloud system $k^{*}$ factor should then be derived as:

$k^{*}=\left|M_{2}\right|^{3} /|N|\left|M_{3}\right|^{2}$,

where $\|$ is the vertical integral that is for the $p^{\text {th }}$ moment of the spectrum $\left|M_{p}\right|=\int_{0}^{H} M_{p}(h) d h$. In vertically uniform clouds, $k^{*}$ is obviously equal to $\langle k\rangle$. For linearly stratified cloud, assuming $k$ is constant throughout the cloud, $r_{2}^{2}=k^{1 / 3} \alpha^{2 / 3} h^{2 / 3} N^{-2 / 3}$, where $\alpha=C_{\mathrm{w}} /\left(4 / 3 \pi \rho_{\mathrm{w}}\right)$.

It follows that $\left|M_{2}\right|=3 / 5 k^{1 / 3} \alpha^{2 / 3} N^{1 / 3} H^{5 / 3}$, and $\left|M_{3}\right|=$ $1 / 2 \alpha H^{2}$, and finally:

$k_{\mathrm{ls}}^{*}=(3 / 5)^{3}(1 / 2)^{-2} k=0.864 k$,

where "ls" holds for linearly stratified.

The data are therefore processed to derive the cloud system mean values of CDNC and of the second and third moments of the droplet spectrum, $\langle N\rangle,\left\langle M_{2}\right\rangle$ and $\left\langle M_{3}\right\rangle$, as proxies for their vertically averaged values, i.e. $|N|=\langle N\rangle H$, and similarly for $\mathrm{M}_{2}$ and $\mathrm{M}_{3} . k^{*}$ is then calculated according to Eq. (7) and plotted in Fig. 7a and b for $\mathrm{Sc}$ and $\mathrm{Cu}$ case studies, respectively. The average values of $k^{*}$, equal to $0.737 \pm 0.061$ and $0.737 \pm 0.047$ for $\mathrm{Sc}$ and $\mathrm{Cu}$ cases, respectively, are very similar for the two cloud types down to the third decimal, with only a slightly greater standard deviation for the Sc cases. The data sets corroborate the above speculation that $k^{*}$ shall be lower than $\langle k\rangle$. The ratio $k^{*} /\langle k\rangle=0.91$ on average for both cloud types merged is slightly greater than the value expected for a linearly stratified convective cloud (0.864) because entrainment-mixing processes partly counteract the linear increase of LWC with height above cloud base, and because $k$ is not constant throughout the cloud (Fig. 5), as assumed above to derive the $k_{1 \mathrm{~s}}$ value.

This methodology, in which $k^{*}$ is derived by averaging the second and third moments of the droplet spectrum instead of averaging locally derived $k$ values, is more suited to quantify the Twomey effect. Interestingly, it does not reveal any relationship between $k^{*}$ and CDNC. It minimizes the impact of very diluted or drizzling samples that indeed do not contribute to cloud radiative properties. For instance, the estimation of $k^{*}$ based on the full droplets and drizzle drops range, as in Sect. 4.2 for the ACE-2 and DYCOMS-II campaigns, 
a) Stratocumulus cases

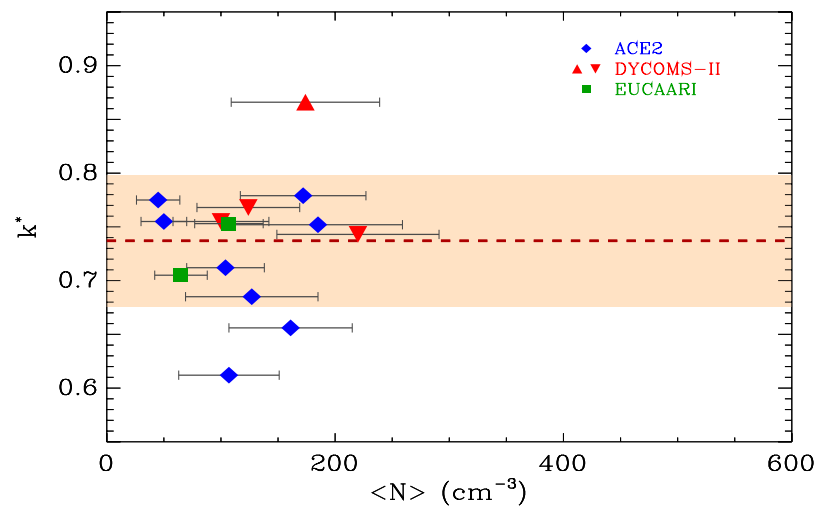

b) Cumulus cases

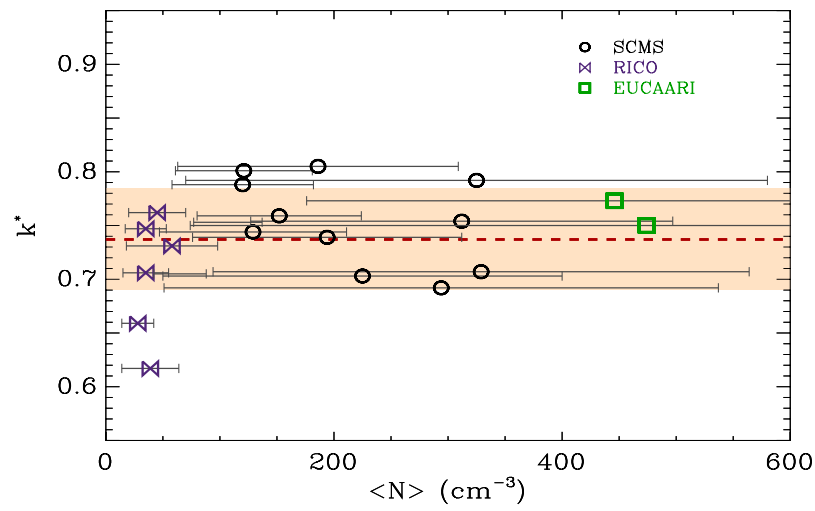

Fig. 7. Same as Fig. 6 for $k^{*}$ values.

results in a much smaller reduction of $2.6 \%$ on average (from 0.727 to 0.708 ), against $6 \%$ for $\langle k\rangle$.

To account for the ubiquitous heterogeneity of the microphysics in convective clouds, both horizontally and vertically, GCM parameterizations of the first aerosol indirect effect should therefore use a constant $k^{*}$ factor of 0.74 instead of the 0.81 obtained above for $\langle k\rangle$.

\subsection{Prediction of CDNC in GCMs}

All the results reported above are based on CDNC values actually measured in clouds. These CDNC values result from $\mathrm{CCN}$ activation at cloud base followed by entrainmentmixing dilution. In most GCMs, the $\mathrm{CCN}$ activation process is parameterized relying on aerosol properties (AbdulRazzac and Ghan, 2000) and, for the most sophisticated schemes, on a prediction of the peak values of vertical velocity at cloud base (Ming et al., 2007; Hoose et al., 2009). An estimate of this initial concentration, referred to as $N_{\text {act }}$, can be obtained from observations when data are available in quasi-adiabatic cloud cores, just above cloud base after $\mathrm{CCN}$ activation is completed and before CDNC is diluted by entrainment-mixing processes. Such samples are however not systematically available in the $\mathrm{Cu}$ data set but we found that the 90th percentile of the measured CDNC frequency distribution in updraft cores provides a satisfactory estimate of $N_{\text {act }}$.

The $N_{\text {act }}$ parameter was more precisely estimated in ACE2 as the average of the CDNC distribution generated with $10 \mathrm{~Hz}$ samples selected in the range of altitude from $40 \%$ to $60 \%$ of the cloud geometrical thickness, void of drizzle, and with a LWC adiabatic fraction $q_{\mathrm{c}} / q_{\mathrm{cad}}$ greater than $90 \%$ (Table 1 in Pawlowska and Brenguier, 2003). The same procedure is applied here over the subset of ascents and descents but with slightly modified criterions adapted to the lower resolution $(1 \mathrm{~Hz}$ instead of $10 \mathrm{~Hz})$ : altitude from $20 \%$ and $80 \%$ of the cloud layer thickness and $q_{\mathrm{c}} / q_{\mathrm{cad}}>75 \%$. In addition rather than using a single value for a whole flight the cloud base level is determined for each sounding separately to take into account its variability.

During DYCOMS-II the peak CDNC values fluctuate significantly along the circle flown by the aircraft (Burnet and Brenguier, 2007). As a result the $N_{\text {act }}$ values determined for each of the selected soundings independently are roughly within a factor of two except in RF07 that has more uniform values. For the EUCAARI flights, this variability is similar, with, for instance during the 15/05 flight, $N_{\text {act }}$ ranging from 94 to $177 \mathrm{~cm}^{-3}$ in the morning and from 47 to $93 \mathrm{~cm}^{-3}$ in the afternoon.

The results are summarized in Table 4 and displayed in Fig. 8. As already noticed in Fig. 4 for $\left\langle q_{\mathrm{c}} / q_{\text {cad }}\right\rangle$, the two cloud types show noticeable differences in both CDNC and LWC adiabatic fractions, with no overlap between the two distributions. The values of the CDNC adiabatic fraction $\left\langle N / N_{\text {act }}\right\rangle$ in Sc $(0.72$ to 0.96$)$ are greater than in $\mathrm{Cu}$ cases (0.32 to 0.56). Note also that, in isolated cumuli, the CDNC adiabatic fraction ( 0.46 in average) is greater than the LWC one (0.27 in average), while they are similar in Sc (0.87 and 0.83 , respectively). This feature reflects the above statement about the contrasting impacts of entrainment-mixing processes in the two cloud types, more homogeneous in isolated cumuli, where the LWC dilution is accounted for by reductions of both CDNC and the droplet sizes, than in stratocumulus layers, where it is mainly due to a $\mathrm{CDNC}$ reduction at constant sizes.

In summary, if CDNC is predicted in a GCM using a parameterization scheme of $\mathrm{CCN}$ activation that does not include the dilution effect of entrainment-mixing processes, this predicted CDNC value shall first be multiplied by the adiabatic fraction $N / N_{\text {act }}$ before entering in the calculation of radiative transfer.

\section{Discussion}

In this analysis of cloud microphysics data sets, we have raised an instrumental and two methodological issues. First, the $k$ factor derived from FSSP-100 measurements is underestimated because of instrumental spectrum broadening. 


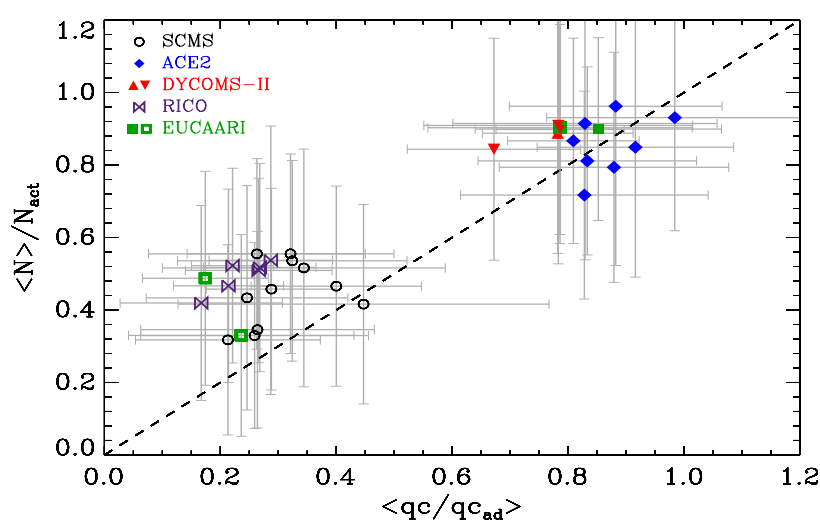

Fig. 8. Scatterplot of the CDNC adiabatic fraction as function of the LWC adiabatic fraction.

Moreover, if the first size class that is affected by spurious droplet counts is accounted for, the $k$ factor decreases with the mean volume diameter. Second, in the various data sets that have been analyzed since Martin et al. (1994) observations, the $k$ factor was derived locally, most often from $1 \mathrm{~Hz}$ samples (about $100 \mathrm{~m}$ ) of the liquid water content and light extinction. Moreover in Martin et al. (1994), the analysis was restricted to undiluted samples that represent only a limited fraction of the cloud systems. The local $k$ values were then averaged to derive a cloud system representative value $\langle k\rangle$. The Twomey hypothesis, however, pertains to the cloud optical thickness and liquid water path, i.e. to the vertical integrals of these local parameters. To account for the vertical integral, we introduce a $k^{*}$ factor that is derived from mean values of the optical thickness, liquid water path and column concentration. $\langle k\rangle=k^{*}$ only if cloud microphysics is vertically uniform, while in situ measurements and simple cloud models all agree in showing that vertical stratification of the microphysics is ubiquitous. Using the parcel model of adiabatic cloud in which the liquid water content increases linearly with height above cloud base, we demonstrate that $k_{\mathrm{ls}}^{*}=0.864\langle k\rangle$, if $k$ is constant throughout the cloud. The data sets corroborate this statement, although with a ratio $k^{*} /\langle k\rangle$ slightly greater (0.91) than expected, because entrainment-mixing processes counteract the linear increase of the LWC in convective clouds and $k$ is not constant throughout the cloud. We have used here a simple model of vertical stratification, but note that the same issue arises at each altitude level when integrating horizontally light extinction and LWC, since microphysics is not horizontally uniform.

More generally, airborne data bases contain at least two physical parameters, the total cloud droplet number concentration and the liquid water content. Other physical parameters such as integral radius (first moment), light extinction (second moment), or reflectivity (sixth moment) are not commonly archived. Instead, the droplet spectrum is character- ized by the radii of the $p$ moments $r_{p}=\left(M_{p} / N\right)^{1 / p}$, where $p=1,2,6$ for the integral radius, light extinction, and reflectivity, respectively. A radius value $(\mu \mathrm{m})$ is indeed easier to interpret than a reflectivity $\left(\mu \mathrm{m}^{6} \mathrm{~cm}^{-3}\right)$ for instance, but one shall keep in mind that such parameters shall not be averaged to derive large scale estimates of physical parameters. For the same reason that in fluid dynamics, extensive variables can be averaged, while mean values of intensive variables are generally meaningless and biased, moments of the droplet size distribution can be averaged, but characteristic radii of the droplet spectrum shall not be. This is also true for any combination of these parameters, such as the $k$ factor that is derived from the second and third moment radii.

These results have been obtained using droplet spectra only, while, in principle, drizzle also contributes to cloud radiative properties. Combining droplet spectrometers with drizzle probes, $k^{*}$ values have been derived that are only $2 \%$ smaller than the ones based on droplets only. Moreover, to be consistent with GCM parameterizations in which radiative transfer is derived from cloud water, excluding precipitating water, we recommend to use the $k^{*}$ values empirically derived from droplet spectra only.

The third issue pertains to the adequacy of a data set to derive large scale cloud properties. Isolated cumuli exhibit highly variable microphysical properties during their short lifetime, with the cloud depth reaching a maximum before a cloud collapses and disappears. Moreover, these clouds are growing in a dry environment and entrainment-mixing processes generate significant heterogeneities in the microphysical fields and dilution of the droplet number concentration. The analysis of the $\mathrm{Cu}$ data set, in fact, reveals that most of the $k$ factor variability arises from differences in the level of dilution of the cloud system as a whole. Aircraft provide snapshots of these highly variables properties, so that an ideal data set should supply uniform sampling of all levels from cloud base to the maximum depth, over all stages of cloud development, from the active growth phase to dissipation. The authors are not aware of such an ideal data set.

The data set issue is less critical for the stratocumulus clouds case study. Indeed only the subset of ascents and descents through the cloud layer are analysed here to provide a uniform sampling from cloud base to cloud top. Sampling biases are thus significantly reduced.

With more than $1000 \mathrm{~km}$ of cloud samples in isolated $\mathrm{Cu}$ and more than $1000 \mathrm{~km}$ of soundings in Sc cloud layers, these data sets do not reveal any relationship between the $k^{*}$ factor and the mean droplet number concentration, that might mitigate the Twomey effect. Note however that if the maximum mean CDNC value exceeds $450 \mathrm{~cm}^{-3}$ in the $\mathrm{Cu}$ data set, it is limited to $220 \mathrm{~cm}^{-3}$ in the $\mathrm{Sc}$ one. 


\section{Conclusions}

In situ microphysical measurements from past field experiments have been revisited to quantify the relationship between optical thickness, liquid water path and cloud droplet number concentration that form the basis of the Twomey hypothesis, namely that cloud optical thickness increases as $N^{1 / 3}$, at constant liquid water path. To account for the width of the droplet spectra and the resulting bias between the mean surface (light extinction) and mean volume (LWC) droplet radii, Martin et al. (1994) refined the Twomey postulate showing that the cloud optical thickness rather increases as $(k N)^{1 / 3}$, where $k<1$. If, however, $k$ decreases when $N$ increases, as resulting from the parameterization suggested by Martin et al. (1994), the first aerosol indirect effect is weaker than anticipated by Twomey.

Such a relationship has therefore been implemented in some GCM parameterizations of the first aerosol indirect effect, with a lower $k$ factor in polluted clouds compared to the pristine ones.

Our analysis of isolated cumuli and stratocumulus deck data bases reveals a noticeable variability of the $k$ factor, but no detectable trend with CDNC. This data set encompasses a wide range of microphysical conditions except Sc in heavily polluted air masses. We therefore conclude that the $k$ factor differences between pristine and polluted clouds that have been extensively discussed in the literature since the original Martin et al. observations are biased by instrumental spectrum broadening, different levels of dilution in the sampled clouds, rejection of diluted samples, and, most importantly, averaging local $k$ values instead of averaging cloud optical thickness, LWP and CDNC to derive unbiased values.

Our analysis also corroborates numerous observational studies of boundary layer clouds, suggesting that the LWC adiabatic fraction is greater in stratocumulus layers than in isolated cumuli, where lateral entrainment has more impact on cloud microphysics. The CDNC adiabatic fraction is close to the LWC one in Sc while it is slightly greater in $\mathrm{Cu}$, thus reflecting the more homogeneous mixing type of $\mathrm{Cu}$ clouds compared to the $\mathrm{Sc}$ one.

A parameterization of the first indirect effect in GCMs begins with a prediction of the droplet number concentration, $N_{\text {act }}$. If it is based on a CCN activation scheme, and assuming the scheme is accurate, this initial CDNC value shall first be reduced by an adiabatic fraction $k_{\text {act }}=N / N_{\text {act }}$. If the cloud scheme discriminates boundary layer stratocumulus and isolated convection, values of 0.87 and 0.46 shall be used for the two cloud types, respectively. Otherwise, a single value of $k_{\text {act }}=0.67$ appears as a good compromise.

Once the mean CDNC value is estimated, calculations of optical thickness can be performed using Eqs. (5) or (6), depending on the assumed vertical profile of LWC, with a constant value of the $k$ factor. To account for the ubiquitous vertical stratification of the convective clouds a value intermediate between the mean $k$ value and the one correspond- ing to a linearly stratified cloud shall be used. Based on the analysis of the SCMS, ACE-2, DYCOM-II, RICO and EUCAARI data sets, the authors recommend a common value $k^{*}$ for stratocumulus clouds and for isolated cumuli: 0.74 seems the best compromise for parameterizations of the first aerosol indirect effect.

In summary the cloud optical thickness is derived for vertically stratified clouds as:

$\tau=A^{\prime}\left(k^{*} k_{\text {act }} N_{\text {act }}\right)^{1 / 3} W^{5 / 6}$,

and for vertically uniform clouds as:

$\tau=\frac{3}{2 \rho_{\mathrm{w}}} \frac{W}{r_{\mathrm{e}}}$,

with $r_{\mathrm{e}}=\left(q_{\mathrm{c}} / 4 / 3 \pi \rho_{\mathrm{w}} k^{*} k_{\text {act }} N_{\text {act }}\right)^{1 / 3}$.

In this formula, our analysis suggests that $k^{*}$ is empirically assessed with an uncertainty of less than $10 \%$. The uncertainty on the adiabatic fraction $k_{\text {act }}=N / N_{\text {act }}$ is greater, of the order of 20 to $50 \%$ even if $\mathrm{Cu}$ and $\mathrm{Sc}$ are treated separately. Prediction of $N_{\text {act }}$ is a challenge that cumulates uncertainties on the aerosol particle properties, including their ability to act as $\mathrm{CCN}$, and the prognostic of the subgrid vertical velocity that drives the activation process. It is currently admitted that the uncertainty on the resulting droplet concentration after CCN activation is more than a factor of 2 . In terms of relative uncertainty, the three parameters $k^{*}, k_{\text {act }}$ and $N_{\text {act }}$ contribute to the optical thickness with a $1 / 3$ power. The contribution of the LWP is more than twice stronger ( $5 / 6$ for vertically stratified and 1 for vertically uniform clouds) and LWP is probably the most uncertain parameter in a GCM. It is thus highly recommended to focus forthcoming efforts on improvements of the bulk cloud properties (liquid water path and cloud fraction), on the parameterization of the cloud base vertical velocity for $\mathrm{CCN}$ activation and on the characterization of the aerosol properties in GCMs.

The present study is limited to a cloud system approach at scales relevant to present GCM simulations and planeparallel radiative transfer calculations. With the refinement of the model resolution and improvement of radiative transfer code to account for the vertical stratification, as discussed in Brenguier et al. (2000b), the results presented here will have to be improved via more systematic studies of the spatial variability of the $k$ factor, especially along the vertical and with the cloud type, focusing on studies of similar clouds in different airmass conditions, or of different clouds in similar airmass conditions.

Acknowledgements. This study has been partially supported by Météo-France, the Netherlands Organization for Scientific Research under Grant 854.00.032, and by the European Commission 6th Framework program project EUCAARI (European Integrated project on Aerosol Cloud Climate and Air Quality interactions) No 036833-2. Flight hours of SAFIRE ATR-42 during IMPACT partly funded by AEROCLOUDS/ANR. The authors are grateful to the teams of the NCAR-C130, of the Météo-France Merlin-IV, 
of the SAFIRE ATR-42 and of the Météo-France TRAMM for the data processing. Moreover the authors acknowledge the contribution of all the participants involved in SCMS, ACE-2, DYCOMS-II, RICO and IMPACT field campaigns. The manuscript was significantly improved by the comments of three anonymous reviewers. DYCOMS-II and RICO data other than Fast-FSSP measurements were provided by NCAR/EOL under sponsorship of the National Science Foundation (http://data.eol.ucar.edu/).

Edited by: V.-M. Kerminen

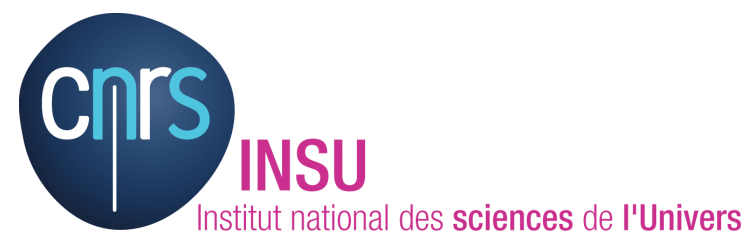

The publication of this article is financed by CNRS-INSU.

\section{References}

Abdul-Razzak, H. and Ghan, S. J.: A parameterization of aerosol activation: 2. Multiple aerosol types, J. Geophys. Res., 105, 6837-6844, 2000.

Baumgardner, D., Strapp, W. J., and Dye, J. E.: Evaluation of the Forward Scattering Spectrometer Probe. Part II: Corrections for coincidence and dead-time losses. J. Atmos. Oceanic Technol., 2, 626-632, 1985.

Bower, K. N., and Choularton, T. W.: A parameterization of the effective radius of ice free clouds for use in global climate models, Atmos. Res., 27, 305-339, 1992.

Brenguier, J.-L.: Coincidence and dead-time corrections for particle counters. Part II: High concentration measurements with an FSSP, J. Atmos. Oceanic Technol., 6, 585-598, 1989.

Brenguier, J. L.: Parameterization of the Condensation Process: A Theoretical Approach, J. Atmos. Sci., 48, 264-282, 1991.

Brenguier, J. L., Baumgardner, D., and Baker, B.: A review and discussion of processing algorithms for FSSP concentration measurements, J. Atmos. Oceanic. Technol., 11, 1409-1414, 1994.

Brenguier, J. L., Bourrianne, T., Coelho, A., Isbert, J., Peytavi, R., Trevarin, D., and Wechsler, P.: Improvements of droplet size distribution measurements with the Fast-FSSP, J. Atmos. Oceanic. Technol., 15, 1077-1090, 1998.

Brenguier, J. L., Chuang, P. Y., Fouquart, Y., Johnson, D. W., Parol, F., Pawlowska, H., Pelon, J., Schüller, L., Schröder, F. and Snider, J. R.: An overview of the ACE-2 CLOUDYCOLUMN Closure Experiment, Tellus, 52B, 814-826, 2000a.

Brenguier, J. L., Pawlowska, H; Schüller, L., Preusker, R., Fischer, J., and Fouquart, Y.: Radiative properties of boundary layer clouds: droplet effective radius versus number concentration, J. Atmos. Sci., 57, 803-821, 2000b.

Burnet, F. and Brenguier, J. L.: Validation of droplet spectra and liquid water content measurements, Phys. Chem. Earth (B), 24, 249-254, 1999.

Burnet, F. and Brenguier, J. L.: Comparison between standard and modified forward scattering spectrometer probes during the small cumulus microphysics study, J. Atmos. Ocean. Tech., 19, 15611931, 2002.

Burnet, F. and Brenguier, J. L.: Observational study of the entrainment-mixing process in warm convective clouds, J. Atmos. Sci., 64, 1995-2011, 2007.

Burnet, F. and Brenguier, J. L.: The onset of precipitation in warm convective clouds: A case study from SCMS, Q. J. Roy. Meteor. Soc., 36, 374-381, doi:10.1002/qj.552, 2010.

Chen, W.-T., Nenes, A., Liao, H., Adams, P. J., Li J.-L. F., and Seinfeld, J. H.: Global climate response to anthropogenic aerosol indirect effects: Present day and year 2100, J. Geophys. Res., 115, D12207, doi:10.1029/2008JD011619, 2010.

Coakley Jr., J. A., Bernstein, R. L., and Durkee, P. A., Effect of Ship-Stack Effluents on Cloud Reflectivity, Science, 237, 10201022, 1987.

Durkee, P. A., Noone, K. J., and Bluth, R. T.: The Monterey Area Ship Track Experiment, J. Atmos. Sci., 57, 2523-2541, 2000.

Dye, J. E. and Baumgardner, D.: Evaluation of the Forward Scattering Spectrometer Probe. Part I: Electronic and optical studies, J. Atmos. Ocean. Technol., 1, 329-344, 1984.

Göke, S., Ochs III, H. T., and Rauber, R. M.: Radar analysis of precipitation in maritime versus continental clouds near the Florida coast: Inferences concerning the role of $\mathrm{CCN}$ and giant nuclei, J. Atmos. Sci., 64, 3695-3707, 2007.

Geoffroy, O., Brenguier, J.-L., and Burnet, F.: Parametric representation of the cloud droplet spectra for LES warm bulk microphysical schemes, Atmos. Chem. Phys., 10, 4835-4848, doi:10.5194/acp-10-4835-2010, 2010.

Hansen, J. E. and Travis, L. D.: Light scattering in planetary atmospheres, Space Sci. Rev., 16, 527-610, doi:10.1007/BF00168069, 1974.

Hoose, C., Kristjànsson, J. E., Iversen, T., Kirkevag, A., Seland, Ø., and Gettelman, A.: Constraining cloud droplet number concentration in GCMs suppresses the aerosol indirect effect, Geophys. Res. Lett., 36, L12807, doi:10.1029/2009GL038568, 2009.

Hudson, J. G. and Yum, S. S.: Maritime-continental drizzle contrasts in small cumuli, J. Atmos. Sci., 58, 915-926, 2001.

Jones, A., Roberts, D. L., Woodage, M. J., and Johnson, C. E.: Indirect sulphate aerosol forcing in a climate model with an interactive sulphur cycle, J. Geophys. Res., 106(D17), 20293-20310, 2001.

Knight, C. A. and Miller, L. J.: Early radar echoes from small, warm cumulus: Bragg and hydrometeor scattering, J. Atmos. Sci., 55, 2974-2992, 1998.

Kulmala, M., Asmi, A., Lappalainen, H. K., Carslaw, K. S., Pöschl, U., Baltensperger, U., Hov, Ø., Brenquier, J.-L., Pandis, S. N., Facchini, M. C., Hansson, H.-C., Wiedensohler, A., and O'Dowd, C. D.: Introduction: European Integrated Project on Aerosol Cloud Climate and Air Quality interactions (EUCAARI) - integrating aerosol research from nano to global scales, Atmos. Chem. Phys., 9, 2825-2841, doi:10.5194/acp-9-2825-2009, 2009.

Liu, Y. and Daum, P. H.: Indirect warming effect from dispersion forcing, Nature, 419, 580-581, 2002.

Liu, Y., Daum, P. H., Guo, H., and Peng, Y.: Dispersion bias, dispersion effect and the aerosol-cloud conundrum, Environ. Res. Lett., 3, 045021, doi:10.1088/1748-9326/3/4/045021, 2008.

Martin, G. M., Johnson, D. W., and Spice, A.: The measurement and parameterization of effective radius of droplets in warm stra- 
tocumulus clouds, J. Atmos. Sci., 51, 1823-1842, 1994.

McFarquhar, G. M. and Heymsfield A. J.: Parameterizations of INDOEX microphysical measurements and calculations of cloud susceptibility: Applications for climate studies, J. Geophys. Res., 106(D22), 28675-28698, 2001.

Ming, Y., Ramaswamy, V., Donner, L. J., Phillips, V. T. J., Klein, S. A., Ginoux, P. A., and Horowitz, L. W.: Modeling the Interactions between Aerosols and Liquid Water Clouds with a SelfConsistent Cloud Scheme in a General Circulation Model, J. Atmos. Sci., 64, 1189-1209, 2007.

Pawlowska, H. and Brenguier, J.-L.: Microphysical properties of stratocumulus clouds during ACE-2, Tellus, 52B, 867-886, 2000.

Pawlowska, H. and Brenguier, J.-L.: An Observational Study of Drizzle Formation in Stratocumulus Clouds during ACE-2 for GCM parameterizations PACE Topical Issue, J. Geophys. Res., 108(D15), 8630, doi:10.1029/2002JD002679, 2003.

Pawlowska, H., Grabowski, W. W., and Brenguier, J-.L.: Observations of the width of cloud droplet spectra in stratocumulus, Geophys. Res. Lett., 33, L19810, doi:10.1029/2006GL026841, 2006.

Peng, Y. and Lohmann, U.: Sensitivity study of the spectral dispersion of the cloud droplet size distribution on the indirect aerosol effect, Geophys. Res. Lett., 30, 1507, doi:10.1029/2003GL017192, 2003.

Raes, F., Bates, T., McGovern, F., and Van Liederkerke, M.: The 2nd Aerosol Characterization Experiment (ACE-2): general overview and main results, Tellus, 52B, 111-125, 2000.

Rauber, R. M., Stevens, B., Ochs III, H. T., Knight, C., Albrecht, B. A., Blyth, A. M., Fairall, C.W., Jensen, J. B., Lasher-Trapp, S. G., Mayol-Bracero, O. L., Vali, G., Anderson, J. R., Baker, B. A., Bandy, A. R., Burnet, F., Brenguier, J-L., Brewer, W. A., Brown, P. R. A., Chuang, P., Cotton, W. R., Di Girolamo, L., Geerts, B., Gerber, H., Göke, S,. Gomes, L., Heikes, B. G., Hudson, J. G., Kollias, P., Lawson, R. P., Krueger, S. K., Lenschow, D. H., Nuijens, L., O'Sullivan, D. W., Rilling, R. A., Rogers, D. C., Siebesma, A. P., Snodgrass, E., Stith, J. L., Thornton, D. C., Tucker, S., Twohy, C. H., and Zuidema, P.: Rain in (Shallow) Cumulus over the Ocean - The RICO Campaign, B. Am. Meteor. Soc., 88, 1912-1928, 2007.
Rotstayn, L. D. and Liu, Y.: Sensitivity of the first indirect aerosol effect to an increase of cloud droplet spectral dispersion with droplet number concentration, J. Climate, 16, 3476-3481, 2003.

Stephens, G. L.: Radiation profiles in extended water clouds. II: Parameterization schemes, J. Atmos. Sci., 35, 2123-2132,1978.

Stevens B., Lenschow, D. H., Vali, G., Gerber, H., Bandy, A., Blomquist, B., Brenguier, J-L., Bretherton, C. S., Burnet, F., Campos, T., Chai, S., Faloona, I., Haimov, S., Friesen, D., Laursen, K, Lilly, D. K., Loehrer, S., Malinowski, S. P., Petters, M. D., Rivera, M., Rogers, D. C., Russell, L., Savic-Jovcic, V., Snider, J., Straub, D., Szumowski, M. J., Takagi, H., Thorton, D. C., Tschudi, M, Twohy, C., Wetzel, M., and van Zanten, M. C.: Dynamics and chemistry of marine stratocumulus - DYCOMSII, B. Am. Meteorol. Soc., 84, 579-593, 2003.

Twomey, S.: Pollution and the planetary albedo, Atmos. Environ., 8, 1251-1256, 1974.

Twomey, S.: The influence of pollution on the shortwave albedo of clouds, J. Atmos. Sci., 34, 1149-1152, 1977.

van de Hulst, H. C: Light Scattering by Small Particles, John Wiley and Sons, New York, 470 pp., 1957.

Warner, J.: The Microstructure of Cumulus Cloud. Part I. General Features of the Droplet Spectrum, J. Atmos. Sci., 26, 1049-1059, 1969.

Wood, R.: Parameterization of the effect of drizzle upon the droplet effective radius in stratocumulus clouds, Q. J. Roy. Meteor. Soc., 126, 3309-3324, 2000. 